\title{
Memoria, historia y telecomunicaciones
}

\author{
Memory, history and telecommunications
}

Gilles MULTIGNER

Periodista y profesor jubilado UCM

gilles.multigner@gmail.com

Aunque las piedras se dejan transportar, no es tan fácil modificar las relaciones que se han establecido entre las piedras y los hombres.

(Maurice Halbwachs, en La mémoire collective)

\begin{abstract}
Resumen: El acontecer individual y social ha quedado registrado desde los orígenes de la humanidad en el legado material y en los relatos cuya interpretación nos ha sido, y nos es, transmitida a través de la memoria de sus protagonistas y de los testimonios de cronistas e historiadores, por los medios disponibles en cada época. Confluyen en esta descripción nociones que con el transcurso del tiempo se han ido cargando de tintes polisémicos.
\end{abstract}

Las líneas que siguen no tienen otra pretensión que la de proporcionar al lector un inventario básico de referencias y de fuentes, cronológicamente ordenadas, que le permita circular en este tupido bosque, barrido por vientos galos, que, en España, al socaire de una serie de disposiciones y proyectos legales, se ha puesto de actualidad.

Abstract: The individual and social events have been recorded since the origins of humanity in the material legacy and in the stories whose interpretation has been, and is, transmitted to us through the memory of its protagonists and the testimonies of chroniclers and historians, by the means available in each era. In this description, notions converge that over time have become charged with polysemic overtones.

The lines that follow have no other claim than to provide the reader with a basic inventory of references and sources, chronologically ordered, that allows them to circulate in this dense forest, swept by French winds, which in Spain, under the influence of a series of legal provisions and projects, has become current. 
Palabras claves: memoria, historia, telecomunicaciones, recuerdo, guerra, colectivo/a, información, pasado, material

Keywords: memory, history, telecommunications, reminiscence, war, collective, information, past, material

Sumario:

I. Introducción.

II. Memoria.

III. Lugar y deber de memoria.

IV. Memoria histórica, memoria e historia.

V. Noticias recientes.

VI. Telecomunicación(es)

VII. A modo de sugerencias para que el lector saque sus conclusiones.

Recibido: noviembre de 2020.

Aceptado: enero 2021. 


\section{INTRODUCCIÓN}

La mayoría de las personas cree tener un conocimiento cabal del significado de los tres términos que componen el título de las presentes reflexiones.

¿Quién no está familiarizado, especialmente ahora en tiempos de pandemia, con palabras tales como teletrabajo, teleasistencia o la propia telemática (vocablo, cuya paternidad, desde hace más de cuatro décadas, reivindica un ingeniero de telecomunicación español, Luis Arroyo Galán ${ }^{1}$, frente a la atribuida a los autores de La informatización de la sociedad, los franceses Simon Nora y Alain Minc ${ }^{2}$ )?

¿Quién no lo está con el sustantivo historia, y no digamos con el calificativo histórico, que tanto sirve para describir ese gol con el que ese no menos legendario delantero de la Unión Deportiva Balompédica acabó con la imbatibilidad del Club Atlético Libertadores, como para traducir la emoción que experimenta el tribuno al descorrer la cortina que oculta el nombre de la calle que a partir de entonces llevará el nombre de su padre, alcalde del pueblo durante cuarenta y cuatro años consecutivos?

¿Y quién no lo está con esa dichosa memoria, prodigiosa o desfalleciente, que permite recordar lo insignificante y olvidar lo que da sentido a la vida y a la muerte, a veces conjugada a secas, otras tildada, también de histórica, cuando no, más recientemente, de democrática?

A poco que nos adentremos por el primer sendero marcado por la que terminaremos denominando historia, el de la búsqueda del conocimiento, atisbaremos que los campos semánticos en los que se inscriben estas tres voces son mucho más extensos que los predios en los que habitualmente los cultivamos. Y no digamos si las asociamos, conforme sugiere el enunciado. Los iremos explorando por el orden que guardan en éste y dentro del contexto en que se relacionan.

\footnotetext{
1 “Telemática", en Novática, no 15 (mayo-junio 1977) 39.

${ }^{2}$ Informe elevado al presidente de la República francesa el 20 de enero de 1978.
} 
A la telemática le ocurre algo parecido a lo que le sucedía a M. Jourdain: recurrimos a ella a diario, cada vez más personas y más a menudo, sin saberlo o, lo que es peor, haciendo un uso de ella que no es precisamente el que le auguraba Luis Arroyo, es decir, el de optimizar esa esencia vital que llamamos información ${ }^{3}$. A finales de los setenta no se habían acuñado aún expresiones como posverdad o fake news, locución esta última a cuya difusión ha contribuido notablemente Donald Trump; pero hacía tiempo que la GPU (¡nada que ver con una Graphic Processing Unit cualquiera!) había sacado a pasear la dezinformatsia, la desinformación ${ }^{4}$. No es cuestión de equiparar telemática con desinformación, pero justo es reconocer cuánto ha potenciado aquella la propagación de esta. Pese a que tal conducta reprobable, definida por la RAE como el resultado de dar información manipulada intencionadamente para conseguir ciertos fines, no constituye en España, ni en la UE, un ilícito penal, la Orden PCM/1030/ 2020 , de 30 de octubre de $2020^{5}$, consagrada a esta cuestión y que trae causa de las preocupaciones de la Comisión Europea, reproduce 59 veces la palabra a lo largo de sus ocho páginas.

\section{MEMORIA}

La memoria, en su sentido de recuerdo o, casi mejor, trascendente, es el primer atajo que vamos a recorrer. Si bien vinculado en su primera acepción a la mente del sujeto, no se trata de aprisionarlo en la individualidad, sino de abordarlo en su dimensión social. Comprobaremos como, con el paso del tiempo, ese traje lo convierte en el reflejo de una sucesión de espejos deformantes.

Sólo puede recordar algo quien o quienes lo han vivido o han tenido conocimiento de ello por otras fuentes. El segundo supuesto está sujeto a múltiples factores que pueden alterar la exactitud de la representación. Pero el primero tampoco es ajeno a una posible distorsión de la remembranza. De ahí la dificultad de enunciar planteamientos irrebatibles. Intentaré evitar que excedan de los límites de lo rigurosamente exigible.

La noción de Memoria Histórica, formulación que, según Pellistrandi ${ }^{6}$, "se ha impuesto en el debate social, cultural y científico desde mediados de

${ }^{3}$ Ibid. Nota 1

4 Vid MORENO ESPINOSA, P., "Comunicación y desinformación en el contenido periodístico”, en J GÓMEZ Y MÉNDEZ SEVILLA, J.M. (coord.), Información y ciencia, Universidad de Sevilla, 1995, pp. 103-110.

${ }^{5} \mathrm{BOE} \mathrm{n}^{\circ} 292$ del 5 de noviembre.

${ }^{6}$ PELLISTRANDI, B., "La mémoire historique entre concept historiographique, fonction sociale et enjeu moral", en Les failles de la mémoire: Théâtre, cinéma, poésie et roman: les mots contre l'oubli. Rennes: Presses universitaires de Rennes, 2016: http://books.openedition.org/pur/55724. 
los años de 1980", nace, crece y se multiplica en Francia, donde se detecta en el rastro de las secuelas que ha dejado la Primera Guerra mundial ${ }^{7}$.

Esto no implica en modo alguno que no haya prendido o no se haya desarrollado en otros países. Vaya a título de clarificación la observación del profesor de la Universidad de Münster, Bernd $Z_{y m e k}{ }^{8}$, a propósito del suyo: "El ejemplo alemán desemboca en la conclusión de que los acontecimientos dolorosos sólo pueden formar parte de una memoria colectiva y de la identidad nacional si la sociedad (o, en primer lugar, algunos grupos sociales) es capaz de entablar, más allá de esos dolorosos acontecimientos históricos, debates políticos e históricos. Sólo a través del debate público puede un acontecimiento histórico convertirse en parte de la memoria de los grupos sociales y de la sociedad". Grupos y sociedad, no hace falta decirlo, que requieren de un sistema enmarcado en un régimen democrático.

En julio de 1919, cuando no ha transcurrido todavía un mes desde la firma del Tratado de Versalles, el entonces Comisario general de la República en Estrasburgo, Alexandre Millerand, excluido hacía quince años del partido socialista y que en 1920 será elegido, sucesivamente, presidente del Consejo de ministros y de la República francesa, reivindica la necesidad de conservar la memoria de los acontecimientos que han marcado el conflicto. A tal fin recaba un informe sobre las zonas de combate, en cuyo contexto se acuña la noción de "recuerdo de guerra". Esta iniciativa, que no concita la unanimidad en el país vecino, dará paso a una "propuesta de ley sobre vestigios y recuerdos de guerra" que, el 8 de noviembre de 1920, iniciará su tramitación en la Cámara de los Diputado, hasta que, a su regreso a esta, el 24 de junio de 1923, tras su paso por el Senado, se le perderá definitivamente la pista.

La Exposición de motivos del fallido proyecto precisaba su finalidad: "Para que no podamos olvidar, para que nuestros hijos recuerden, para que las restantes naciones comprendan y juzguen, conviene que Francia conserve en su rostro la cicatriz de sus heridas". Dos días después, el 10 de noviembre (J.O. 24.11.1920), un Decreto creaba en el seno de la Comisión de Monumentos

DOI : https://doi.org/10.4000/books.pur.55724.

7 JEHIN, Ph., HENSEL (Florian), "Le Lingekopf de 1915 à nos jours", en Revue d'Alsace, 139 (2013). (URL: http://journals.openedition.org/alsace/1815; DOI : https://doi.org/10.4000/alsace.1815).

8 "El proceso dialéctico de la memoria colectiva: el ejemplo de la Alemania de la posguerra", en Revue française de pédagogie, 165 (octobre-décembre 2008). URL: http://journals.openedition.org/ rfp/1050 ; DOI : https://doi.org/10.4000/rfp.1050 
históricos, cuyos orígenes se remontan a 1790, una sección de "vestigios y recuerdos de guerra", que sería suprimida unos años más tarde.

$\mathrm{Y}$ en este punto parece imprescindible señalar que el 31 de diciembre de 1913 (J.O. 4.1.1914), en vísperas de la conflagración, se promulgaba la ley, aprobada por el Senado y la Cámara de Diputados, por la que se clasificaban como monumentos históricos "todos aquellos inmuebles cuya conservación ofrece, desde el punto de vista de la historia o del arte, un interés público"". La destrucción provocada por las hostilidades convierte a muchos de esos inmuebles, cuando no a ciudades enteras, en ruinas. Esta situación suscita la disyuntiva entre reconstruir o conservar el resultado de la devastación ${ }^{10}$. Tal y como evoca Arlette Auduc y recoge Franck Viltart, ${ }^{11}$ en el informe elaborado en 1915 por la Comisión de reparación de los daños de la guerra con ocasión de su visita a la ciudad mártir de Arras, puede leerse que "quizás fuera bueno $[\ldots]$ escoger algunas de estas ruinas y conservarlas intactas para las futuras generaciones. Llevarán a que se comprenda mejor lo que es la guerra y ni siquiera permitirán que se perdone".

Se franqueaba el paso a una sucesión de propuestas tendentes a la conservación de las ruinas, noción tímidamente apuntada, con fines patrimoniales, en la ley de 1913 y manifiestamente políticas en las que arrancaron con la proposición de ley presentada ante la Cámara de diputados por varios representantes el 23 de septiembre de 1915, cuyo encabezamiento destacaba "la salvaje barbarie de las tropas alemanas". Esta proposición no prosperaría, pero en el decenio comprendido entre 1913 y 1923 términos como ruinas, vestigios, recuerdos, van dotándose de un sentido del que antes carecían. Sentido que combina pretensiones pedagógicas y patrióticas, pero, simultáneamente, un cierto afán utilitario, por no decir turístico, ante la atracción de los escenarios de los enfrentamientos, planteamientos que el ejército acoge con beneplácito.

Todos estos aspectos convergen en la "Trinchera de las bayonetas", monumento histórico erigido en Douaumont en conmemoración de la batalla de Verdún,

${ }^{9}$ En España, las disposiciones más relevantes en la materia, cuya protección arranca tímidamente con la Ley de 7 de julio de 1911 (Gaceta del 8), son la Ley de 13 de mayo de 1933 (Gaceta del 25), sobre defensa, conservación y acrecentamiento del Patrimonio Histórico Artístico, y la Ley 16/1985, de 25 de junio (BOE del 29), del Patrimonio Histórico Español.

10 Arras, reconstruida al término de la $1^{\text {a }} \mathrm{GM}$, o Gernika, reedificada tras haber sido arrasada por la Legión Cóndor el 26 de abril de 1937, y el pueblo viejo de Belchite (1937-38) u Oradour-sur-Glane, conservada en el estado a que quedó reducida tras la masacre, saqueo y estragos de los alemanes el 10 de junio de 1944, simbolizan las soluciones aportadas al dilema.

${ }^{11}$ VILTART, F., "Naissance d'un patrimoine : les projets de classement des ruines, vestiges et souvenirs de guerre (1915-1918)", en In Situ, 23 (2014). URL: http://journals.openedition.org/insitu/ 10990 ; DOI: https://doi.org/10.4000/insitu.10990. 
en cuyas proximidades se construiría el Osario que reúne los restos de unos 130.000 combatientes, franceses y alemanes, inmolados en aquél sangriento episodio de la historia.

No puedo evitar referir un testimonio personal que me marcó profundamente hasta el punto de que lo evoqué en uno de mis primeros balbuceos como reportero tribulete en la revista del colegio y, 60 años más tarde, no lo he olvidado. Siendo adolescente, visité aquél "alto lugar de la memoria nacional" francesa, en compañía de unos amigos de mi familia. Difícilmente puede olvidarse la imagen de los huesos amontonados que se pueden observar desde el exterior a través de los ventanucos practicados en el mausoleo. Lo mismo que los miles de cruces que bordean el Osario. Pero lo que me impresionó fueron las bayonetas y los cañones de los fusiles que asomaban en una trinchera colmatada. Lo realmente conmovedor, y me acompañó durante muchos años, era la explicación proporcionada durante la visita: aquellos fusiles y aquellas bayonetas seguían empuñadas por sus propietarios o usuarios que yacían sepultados por el derrumbamiento que se había producido durante un ataque. Era el mito transportado por el imaginario colectivo, deliberadamente transportado, habría que añadir. Pasaron muchos años hasta que, en mi imaginario, los vestigios cedieron el paso a la realidad. Quien mejor lo expresa es Jean Norton $\mathrm{Cru}^{12}$ : "La trinchera de las bayonetas, que al principio no era más que una inocente ingenuidad, se convirtió, mediante algunas complicidades, en una indigna impostura".

A mediados de la década de los 20, un intelectual, Maurice Halbwachs (quien terminará sus días en el campo de concentración de Buchenwald) toma el relevo para reflexionar ${ }^{13}$ sobre la memoria individual, social y colectiva. Un cuarto de siglo después, en su obra póstuma, ${ }^{14}$ lo hace sobre la consistencia y durabilidad de esa memoria colectiva en el espacio y en el tiempo. Para Halbwachs, la memoria colectiva más que un conjunto de memorias individuales es el fundamento de la memoria y la consciencia personales. La memoria, señala, requiere de una base material sin cuya presencia sería muy difícil recordar.

Otro filósofo, Paul Ricœur, en su última obra publicada hace veinte años ${ }^{15}$, discrepa de este planteamiento, que para él equivale a reducir la conciencia

12 CRU (Jean-Norton), Témoins, Nancy, Presses universitaires de Nancy, col. "Histoire contemporaine", 2006.

${ }^{13}$ Les cadres sociaux de la mémoire, Paris, Alcan, 1925.

http://classiques.uqac.ca/classiques/Halbwachs_maurice/cadres_soc_memoire/cadres_soc memoire.html.

${ }^{14}$ La mémoire collective, Paris, Presses Universitaires de France, 1950.

http://classiques.uqac.ca/classiques/Halbwachs_maurice/memoire_collective/memoire_co llective.pdf

${ }^{15}$ La mémoire, l'histoire, l'oubli, Paris, Sœuil, 2000. 
personal a una fuente colectiva, de tal forma que nuestra intimidad tendría su origen fuera de nosotros.

Los juicios de estos dos pensadores nos llevan a la consideración de que la memoria colectiva dura mientras viven los miembros del grupo que la soporta y desaparece con ellos, cediendo entonces el protagonismo a la historia que, a falta de cualquier recuerdo vivo, busca la representación del acontecimiento. Pero al mismo tiempo pone de relieve la importancia de la construcción del símbolo para que perdure la memoria y a la importancia de que este símbolo tenga un trasunto material que lo vehicule. "El propósito de los hombres antiguos", añade Halbwachs, "se plasma en un acondicionamiento material, es decir, en una cosa, y la fuerza de la tradición local proviene de la cosa de la que era imagen".

\section{LUGAR Y DEBER DE MEMORIA}

Pierre Nora (¡no confundir con Simon!), inicia su larga definición de memoria colectiva, noción que opone a la de historia, lo mismo que postula el divorcio entre aquella y la memoria histórica, diciendo que "es lo que queda del pasado en la vivencia de los grupos, o lo que los grupos hacen del pasado". La memoria colectiva, desmenuza, "es el recuerdo o el conjunto de recuerdos, conscientes o no, de una experiencia vivida y/o mitificada por una colectividad viva, de cuya identidad el pasado es parte integrante" ${ }^{\text {"16 }}$. Este enfoque anticipa el que su autor formalizará en la ambiciosa obra que impulsará y dirigirá años más tarde y que lleva por título el de una noción reintroducida por él en un seminario del EHESS, la de los loci memoriae ${ }^{17}$. "Un lugar de memoria en todos los sentidos de la palabra", afirma, "va desde el objeto más material y concreto, en su caso geográficamente situado, hasta el objeto más abstracto e intelectualmente construido". Término de amplio alcance, como puede apreciarse, en el que caben desde los monumentos a los acontecimientos, pasando por los archivos y los museos y, si se me permite, los relatos históricos...

El debate sobre la relación entre historia y memoria, aunque tuvo un principio, parece no tener fin. Son muchos los historiadores y pensadores reconocidos que han abordado esta cuestión. De soslayo o de forma tan contundente que no admite discusión.

\footnotetext{
16 "La mémoire collective", en La nouvelle histoire, sous la direction de Jacques Le Goff, Paris, Retz-CEPL, 1978.

17 NORA, P. (sous la direction de), Les lieux de mémoire, $1^{\mathrm{a}}$ ed., 7 vols., Paris, Gallimard, 1984-1992.
} 
Así, el escritor británico Tony Judt afirmaba:

Yo creo profundamente en la diferencia entre la historia y la memoria; permitir que la memoria sustituya a la historia es peligroso. Mientras que la historia adopta necesariamente la forma de un registro, continuamente reescrito y reevaluado a la luz de evidencias antiguas y nuevas, la memoria se asocia a unos propósitos públicos, no intelectuales: un parque temático, un memorial, un museo, un edificio, un programa de televisión, un acontecimiento, un día, una bandera. Estas manifestaciones mnemónicas del pasado son inevitablemente parciales, insuficientes, selectivas; los encargados de elaborarlas se ven antes o después obligados a contar verdades a medias o incluso mentiras descaradas, a veces con la mejor de las intenciones, otras veces no. En todo caso, no pueden sustituir a la historia ${ }^{18}$.

Tomo la extensa cita de un artículo de Fernando Savater ${ }^{19}$, quien se pronuncia en el mismo sentido: La verdad es que la memoria y la historia no son ni mucho menos lo mismo y tratar de homogeneizarlas por decreto o por acuerdo político es cosa estrictamente imposible y probablemente indeseable. El contexto (la paz en Euskadi) de la tribuna del filósofo donostiarra y su reflexión exceden del contenido del presente trabajo; la he traído aquí a colación porque la opinión de Judt a propósito de la memoria constituye un argumentario que, sin ningún esfuerzo, podría trasladarse a la historia.

En su espléndida tesis doctoral ${ }^{20}$ sobre un dramático episodio acontecido en su país, la investigadora argentina Claudia Feld se interroga sobre la noción de memoria y, al analizar sus características en el seno del espacio público, acude al enfoque propuesto por Elizabeth Jelin ${ }^{21}$, que consiste en "entender las memorias como procesos subjetivos, anclados en experiencias y en marcas simbólicas y materiales". Aun cuando se reivindique la diferenciación entre historia y memoria, no es menos cierto que el contraste evidencia su complementariedad.

La obra de referencia para aproximarse a la expresión "Deber de memoria" es sin duda la exhaustiva tesis doctoral consagrada al tema por Sébastien

${ }^{18}$ Pensar el siglo $X X$, Madrid, Taurus, 2012

19 "Ética por los suelos", El Correo, 5 de octubre de 2013. https://paralalibertad.org/eticapor-los-suelos/

${ }^{20}$ La télévision comme scène de la mémoire de la dictature argentine. Une étude sur les récits et les représentations de la disparition forcée de personnes [La televisión como escenario de la memoria de la dictadura argentina. Un estudio sobre los relatos y las representaciones de la desaparición forzada de personas], dirigida por Armand Mattelart y defendida el 17.5.2004 en la Universidad Paris VIII.

${ }^{21}$ Los trabajos de la memoria, Madrid, Siglo XXI España de Editores, 2002. 
Ledoux. $^{22}$ Tras remontarse a finales de los años ochenta del siglo XIX para localizar "el ensamblaje de dos palabras tomadas, cada una, en su sentido literal", acota nuevamente el empleo de esta misma locución, en dos ocasiones, ajenas la una a la otra, a partir de 1972, hasta que comprueba que "a comienzos de los años de 1980, la expresión se moviliza en varias ocasiones por locutores que desean atestiguar un cambio significativo de la sociedad en su relación con el pasado". Para luego destacar que, al principio del año 1983, Pierre Nora será el primer historiador en recurrir al "deber", cuando no al "imperativo" de memoria.

La definición que recoge en su tesis es precisamente la que incorporó el Petit Larousse Illustré en su edición de 2003: "La obligación moral de dar testimonio, individual o colectivamente, de acontecimientos cuyo conocimiento y transmisión se consideran necesarios para sacar lecciones del pasado (la Resistencia o la Deportación durante la Segunda Guerra mundial, por ejemplo)".

En su trabajo consagra Ledoux numerosas referencias al holocausto. Contexto en el que desmigaja (cuidando de distinguir en esa locución entre expresión, término y noción) un artículo de Olivier Lalieu ${ }^{23}$, publicado en 2001, que inscribe el deber de memoria en el ámbito de la deportación (entendiéndose por tal el traslado forzoso de cientos de miles de franceses a campos de concentración y trabajo nazis), cuya formulación sitúa en 1990 y que "responde a un proceso, que pone de relieve la Shoah, iniciado a finales de los años de 1970". A propósito de la polémica que concita el deber de memoria, observa Lalieu que "Se nutre además de la mezcla de géneros que implica la propia expresión: por un lado, el culto a los muertos que pertenece al orden de lo sagrado y, por otro, los efectos inducidos en los ámbitos históricos, judiciales, financieros y políticos”.

\section{MEMORIA HISTÓRICA, MEMORIA E HISTORIA}

En España, en lo que llevamos de siglo, antes y después de la promulgación de una ley ${ }^{24}$ que congregó a partidarios y detractores, y los sigue congregando, se ha publicado un considerable número de indagaciones y reflexiones sobre estas cuestiones. Hasta donde se me alcanza, no se ha producido ese enconado

${ }^{22}$ Le temps du "Devoir de Mémoire" des années 1970 à nos jours [El tiempo del "Deber de Memoria" desde los años de 1970 hasta nuestros días], dirigida por Denis Peschanski, y defendida el 10 de noviembre de 2014 en la Universidad Paris 1.

23 «L'invention du « devoir de mémoire », en Vingtième Siècle. Revue d'Histoire, no 69 (enero-marzo 2001): https://www.cairn.info/revue-vingtieme-siecle-revue-d-histoire-2001-1page-83.htm

${ }^{24}$ Ley 52/2007, de 26 de diciembre (BOE del 27), por la que se reconocen y amplían derechos y se establecen medidas en favor de quienes padecieron persecución o violencia durante la guerra civil y la dictadura. 
debate entre Historia y Memoria, y mucho menos ese divorcio preconizado o consumado por otros, entre una y otra o entre los distintos apellidos de la segunda. A pesar de que reconocidos historiadores han rechazado "tajantemente" el maridaje de los conceptos, como es el caso del hispanista Stanley G. Payne $^{25}$, quien afirma lapidariamente que "Memoria histórica ni es memoria ni es historia". Sirva como contrapunto el sosegado y minucioso análisis que hacía por aquellas fechas el recientemente desaparecido profesor Santos Juliáa ${ }^{26}$.

Comparto a este respecto la propuesta historiográfica del profesor Juan Sisinio Pérez Garzón, así como las razones que aduce en apoyo de su tesis, conforme a la cual "la Memoria y la Historia ya han quedado definitivamente entrelazadas como formas de relacionarse con el pasado" 27.

La antes mencionada Ley de memoria histórica consagra dos artículos (16 y Disposición adicional sexta) a un peculiar lugar de memoria, el Valle de los Caídos, que pretende convertir en un cauce de reconciliación y convivencia de la sociedad española. Numerosas apelaciones a este monumento contiene también el Anteproyecto de Ley de memoria democrática (palabra esta última que, dicho sea de paso, se reproduce en el texto en 149 ocasiones), conocido a mediados de septiembre pasado, en sus, provisionales, artículo 55, Disposición transitoria y Disposición derogatoria. En esta oportunidad se enfatiza su resignificación como lugar de memoria democrática. En un debate avant-la-lettre, apostillaba Santos Juliá, el monumento puede venirse abajo, y cuando lo haga, habrá resignificado que aquello fue una ruina ${ }^{28}$.

Sea como fuere, cabe, cuando menos, interrogarse sobre la viabilidad de algunos de los objetivos perseguidos por ambos textos legales, cuando se leen las estremecedoras palabras pronunciadas por el entonces Caudillo de España por la gracia de Dios (inquilino más notorio, hoy desahuciado, del edificio que él mismo había mandado construir) el día de su inauguración, 20 años después del final de la contienda civil:

[...] Mucho fue lo que a España costó aquella gloriosa epopeya de nuestra liberación para que pueda ser olvidado; pero la lucha del bien con el mal no termina por grande que sea su victoria. Sería pueril creer

$25<$ El objetivo de la ley de memoria histórica es trazar una línea tajante entre "buenos" y "malos">, entrevista en $A B C, 17$ de diciembre de 2006.

26 "De nuestras memorias y de nuestras miserias", en Hispania Nova, no 7 (2007). http://hispanianova.rediris.es/7/dossier/07d018.pdf

27 "Memoria e Historia: reajustes y entendimientos críticos", en Ayer, 86/2012 (2). https://ruidera.uclm.es/xmlui/bitstream/handle/10578/2504/fi_1346601514-memoria\%20e\%20 historiarev\%20ayer86sisinio.pdf? sequence $=1$ \&isAllowed $=\mathrm{y}$

${ }^{28}$ El País, 19 de marzo de 2018. 
que el diablo se someta; inventará nuevas tretas y disfraces, ya que su espíritu seguirá maquinando y tomará formas nuevas, de acuerdo con los tiempos. La anti España fué vencida y derrotada, pero no está muerta. $[\ldots]^{29}$.

La relación entre la historia y la memoria fluye a través de la remembranza y el olvido. En 2006, declarado Año de la Memoria Histórica, ${ }^{30}$ señalaba también Santos Juliá que la memoria compartida sólo puede construirse sobre la decisión de echar al olvido el pasado. ${ }^{31}$ En relación con el enfrentamiento del que trae causa esta conmemoración, habría que incorporar la palabra perdón, cuyo análisis desborda estas evocaciones, pero del que hay que dejar constancia.

\section{NOTICIAS RECIENTES}

La redacción de las presentes notas está enmarcada en el tiempo con tres noticias que guardan relación, en mayor o menor medida, con las tres voces que les dan título.

- El 1 de octubre pasado el Gabinete de prensa del Ministerio de Fomento y los medios de comunicación anunciaban el futuro traslado del Museo Postal y Telegráfico desde el rincón de Aravaca en el que yace exilado (desde el "Año de la Memoria Histórica", por cierto) hasta el antiguo edificio de Correos en Toledo.

- El pasado 21 de noviembre se conmemoraban los veinte años del asesinato por ETA del político español Ernest Lluch.

- El 25 de noviembre desaparecía el futbolista Diego Armando Maradona.

La primera de las noticias fue difundida por los medios de Castilla La Mancha, antenas locales de los medios nacionales y relevada por las respectivas plataformas digitales. La evocación de la memoria del antiguo ministro catalán fue recogida en la práctica totalidad de los medios informativos nacionales de toda naturaleza. La muerte de Maradona dio la vuelta al mundo conocido en tiempo real desplazando durante varios días las inquietudes, si no de los habitantes del planeta, cuando menos de quienes tienen por cometido dar testimonio del acontecer y del pulso humano.

\footnotetext{
${ }^{29}$ Discurso en la inauguración del Valle de los Caídos, 02 de abril de 1959. http://www.generalisimofranco.com/Discursos/discursos/1959/00003.htm

${ }^{30}$ Ley 24/2006, de 7 de julio (BOE del 8)

31 "Año de Memoria", El País, 31 de diciembre de 2006.
} 
A partir de ahora nadie podrá confundir la "Mano de Dios" (una suerte de tautología si se aplica al difunto) con "el gol del siglo", también conocido como "el mejor gol del mundo", portentos ambos ocurridos en un mismo partido en el lejano año 1986 y protagonizados por el "10" por antonomasia, camiseta que con aguda originalidad han exhibido en sus encuentros numerosos profesionales y aficionados, en homenaje a la figura extinta cuya memoria perdurará por los siglos de los siglos. Es de suponer que cundirá el ejemplo de Massimo Vignati, y que su Sótano-Museo de Nápoles está llamado a expandirse y reproducirse.

El último día del mes de noviembre, el Congreso de los diputados le rendía a Ernest Lluch un homenaje al que se sumaba EH Bildu. No hay que excluir que dentro de un lustro (25 años, un cuarto de siglo, es una cifra redonda) se prodiguen testimonios similares que, mientras estén presididos por el afán de reconciliación son enormemente reconfortantes.

Ya nadie recuerda, si es que alguna vez lo supo, que un fragmento material de la memoria de las telecomunicaciones, nacido en 1865, está a punto de emprender un viaje incierto durante el que corre el riesgo de desprenderse de parte de su impedimenta. De poco consuelo resulta pensar que esta iniciativa se inscribe en el signo de los tiempos (la trayectoria menguante de la otrora espléndida y exuberante Colección histórico-tecnológica de Telefónica, los nubarrones que se ciernen sobre el Museo didáctico de las telecomunicaciones de A Coruña, por no hablar de lo que ocurre allende las fronteras...). La restauración del Castillo del Retiro cuyo inicio se augura para finales de 2021 y el aprovechamiento de alguna dependencia anexa que pertenece a la AEMET, podrían aportarle a Madrid el Museo estatal de telecomunicaciones que la historia le ha negado y el de meteorología por el que muchos profesionales se afanan, en la torre que sirvió de emplazamiento a la telegrafía óptica y al Instituto Central Meteorológico en el siglo XIX.

Partiendo de que Memoria e Historia son complementarias, y comparten un fin común (la búsqueda y la transmisión de verdad, que no "la" verdad), la dificultad estriba en situar los límites, las divisorias, y en tener claras las ideas. En creer que un esqueleto empuña el fusil en el que está calada la bayoneta que asoma por encima de la tierra, o en saber que se trata de evocar el recuerdo de acontecimientos que no deberían haberse producido ni reproducido. En creer que habría que terminar de derribar esas piedras que han desafiado el paso de los años, o en esforzarse en reconstruirlas o mantenerlas para transmitir a las generaciones sucesivas el conocimiento que atesora. Con la ayuda de las telecomunicaciones. 


\section{TELECOMUNICACIÓN(ES)}

El inventor de esta palabra, Édouard Estaunié, la acuñó en singular, ${ }^{32}$ como la transmisión a distancia del pensamiento mediante la electricidad. Sus antepasados acudieron tanto al plural como al singular. Así, Heródoto ${ }^{33}$ atribuía a Mardonio el propósito de avisar al Rey de la toma de Atenas mediante antorchas encendidas en las islas, mientras que Esquilo ${ }^{34}$ se refería al fulgor brillante, a la lumbre, al correo de fuego, que desde el Monte Ida llegaba a Argos para anunciar la conquista de Troya.

El imperio romano, la expansión árabe y los reinos medievales, entre otros, recurrieron, en singular y en plural, a los fuegos y a las señales de humo para comunicarse a distancia. Se perfeccionaron los sistemas en la modernidad con las sucesivas aportaciones de Chappe, Murray, Ximénez Coronado, Betancourt, Lerena o Mathé en el ámbito de la telegrafia ${ }^{35}$ óptica, hasta que los planteamientos teóricos de Charles Morrison o las experiencias de Georges Louis Lesage y la domesticación de la electricidad desembocaron en las invenciones de CookeWheatstone y Morse, entre otros pioneros de la telegrafía eléctrica. Unas décadas más tarde se sumaba el teléfono de Bell, al que seguirían numerosos vástagos.

El afán de Estaunié de dotar de un nombre común a las enseñanzas que se impartían en la Escuela profesional superior de correos y telégrafos de París (las dos anteriores y la recién incorporada radio), cuya dirección ostentaba por designación de Alexandre Millerand, entonces ministro del ramo, le llevó a formular aquella denominación en los términos descritos. Con motivo de las reuniones internacionales que tuvieron lugar en Madrid en 1932, a raíz de las cuales la Unión Internacional Telegráfica se convirtió en Unión Internacional de Telecomunicaciones, se acordó una nueva definición, ${ }^{36}$ más extensa, de estas últimas en la que la palabra "transmisión" era sustituida por la de "comunicación". Voz, esta, que importunaba a algunos y que dio lugar a que la Convención internacional de la UIT, celebrada en Atlantic City en 1947, adoptara la definición que permanece vigente, ${ }^{37}$ si bien, conforme observa Pierre Musso, ${ }^{38}$ "con la

${ }^{32}$ Traité pratique de télécommunication électrique (Télégraphie - Téléphonie), Paris, Dunod, 1904.

${ }^{33}$ Historias, IX, 3.

${ }^{34}$ Agamenón, 274-281.

${ }^{35}$ Un nuevo vocablo, el de "télégraphe" ideado en 1794 por el Conde André François Miot de Melito, a raíz de un encuentro con Claude Chappe.

${ }^{36}$ Toda comunicación telegráfica o telefónica de signos, señales, escritos, imágenes y sonidos de toda naturaleza, por hilo, radio o por otros sistemas o procedimientos de señalización eléctricas o visuales (semáforos).

${ }^{37}$ Toda transmisión, emisión o recepción de signos, señales, escritos, imágenes, sonidos o informaciones de cualquier naturaleza, por hilo, radioelectricidad, medios ópticos u otros sistemas electromagnéticos. 
desregulación [...], la multiplicación de las innovaciones (especialmente la telefonía móvil e Internet), la convergencia de las técnicas digitales y la aparición de nuevos actores, la definición del sector se ha enturbiado. La ruptura es tan profunda que el término "telecomunicaciones" ha sido abandonado por la reglamentación europea que habla ahora de "comunicaciones electrónicas" para referirse a las telecos [sic], las redes cableadas y las redes informáticas". Poco después, al comparar las dos definiciones de la UIT, Jean-Marie Dilhac ${ }^{39}$ señalaba que esta última "aunque muy similar a la primera, evita felizmente tener que definir el término telecomunicaciones al referirse a comunicación, e insiste en la importancia de la transmisión". Opinión que completaba con una nota que acotaba el adverbio "felizmente": "Esta definición [la de 1947] aleja un poco en efecto el inevitable escollo del diccionario demasiado auto referente; además, evita la confusión con el aspecto social de la transmisión de la información".

La distinción entre comunicación y transmisión no es baladí. Ya lo advertía Marshall McLuhan ${ }^{40}$ en su famoso aforismo, "El medio es el mensaje", hoy un tanto olvidado, pero que recobra a diario reforzada actualidad.

\section{A MODO DE SUGERENCIAS PARA QUE EL LECTOR SAQUE SUS CONCLUSIONES}

La evolución de los conceptos no es privativa de la tecnología, en este caso de las telecomunicaciones. Lo mismo se aprecia, como hemos visto, en la noción de memoria, que en la de historia. De la mera narración, investigación o recogida de testimonios, se ha desembocado, a través de los siglos, en la consideración de esta última como una disciplina científica, como una ciencia social, para enfocarla desde un punto de vista historicista, presentista o determinista, entre otras muchas perspectivas.

El virus por excelencia que circula actualmente por el mundo lo hace a gran velocidad y de forma mutante. Lo mismo ocurre con la información, aquejada, simultáneamente de instantaneidad e inestabilidad. Abraham Moles, a propósito de Ralph Hartley, se refería a aquella como la medida de la reducción de la incertidumbre por medio del mensaje. Pero este requiere coherencia y que fluya por un cauce conocido y reconocible. Y nunca ha sido más cierta la máxima heraclitiana de que nunca nos bañamos en las aguas del mismo río.

\footnotetext{
${ }^{38}$ Les télécommunications, Paris, La Découverte, col. Repères, 2008.

${ }^{39}$ Édouard Estaunié, ingénieur, enseignant, romancier, Histelcon 08, Sep 2008, Paris, France, hal-00446427.

${ }^{40}$ Understanding Media: The Extensions of Man, New York, McGraw-Hill, 1964.
} 
Antes aludía a la ayuda de las telecomunicaciones. Sí. Pero teniendo muy presentes los riesgos que implica, hoy, la telemática, vehículo privilegiado de la historia y la memoria.

Como el lector habrá podido comprobar, la temática esbozada es enormemente compleja por cuanto intervienen en su valoración factores pertenecientes a las ideologías y a los sentimientos. He intentado suministrarle un básico inventario y unas referencias bibliográficas en las que, llegado el caso, podrá bucear y extraer sus propias conclusiones. 